\title{
Preventing deaths and injuries from house fires: a cost-benefit analysis of a community-based smoke alarm installation programme
}

\author{
Merissa A Yellman, ${ }^{1}$ Cora Peterson, ${ }^{2}$ Mary A McCoy, ${ }^{1}$ Shelli Stephens-Stidham, \\ Emily Caton, ${ }^{3}$ Jeffrey J Barnard, ${ }^{4}$ Ted 0 Padgett $\mathrm{Jr}^{3}{ }^{3}$ Curtis Florence, ${ }^{2}$ Gregory R Istre ${ }^{1}$
}

\begin{abstract}
- Additional material is published online only. To view please visit the journal online (http://dx.doi.org/10.1136/ injuryprev-2016-042247).

${ }^{1}$ Injury Prevention Center of Greater Dallas, Dallas, Texas, USA

${ }^{2}$ National Center for Injury Prevention and Control, Centers for Disease Control and Prevention (CDC), Atlanta, Georgia, USA

${ }^{3}$ Dallas Fire Rescue Department, Inspection and Life Safety Education Division, Dallas, Texas, USA

${ }^{4}$ The Southwestern Institute of Forensic Sciences, Office of the Medical Examiner, Dallas, Texas, USA
\end{abstract}

\section{Correspondence to}

Dr Cora Peterson, CDC National Center for Injury Prevention and Control, Mailstop F-62, 4770

Buford Highway, Atlanta, GA 30341, USA;

cora.peterson@cdc.hhs.gov

Received 17 October 2016 Revised 14 December 2016 Accepted 18 January 2017 Published Online First 9 February 2017

Check for updates

To cite: Yellman MA Peterson C, McCoy MA, et al. Inj Prev 2018:24:12-18

\begin{abstract}
Background Operation Installation (OI), a communitybased smoke alarm installation programme in Dallas,

Texas, targets houses in high-risk urban census tracts. Residents of houses that received Ol installation (or programme houses) had $68 \%$ fewer medically treated house fire injuries (non-fatal and fatal) compared with residents of non-programme houses over an average of 5.2 years of follow-up during an effectiveness evaluation conducted from 2001 to 2011.
\end{abstract}

Objective To estimate the cost-benefit of Ol. Methods A mathematical model incorporated programme cost and effectiveness data as directly observed in Ol. The estimated cost per smoke alarm installed was based on a retrospective analysis of $\mathrm{Ol}$ expenditures from administrative records, 2006-2011. Injury incidence assumptions for a population that had the Ol programme compared with the same population without the Ol programme was based on the previous Ol effectiveness study, 2001-2011. Unit costs for medical care and lost productivity associated with fire injuries were from a national public database.

Results From a combined payers' perspective limited to direct programme and medical costs, the estimated incremental cost per fire injury averted through the $\mathrm{Ol}$ installation programme was $\$ 128,800$ (2013 US\$). When a conservative estimate of lost productivity among victims was included, the incremental cost per fire injury averted was negative, suggesting long-term cost savings from the programme. The Ol programme from 2001 to 2011 resulted in an estimated net savings of $\$ 3.8$ million, or a $\$ 3.21$ return on investment for every dollar spent on the programme using a societal cost perspective.

Conclusions Community smoke alarm installation programmes could be cost-beneficial in high-fire-risk neighbourhoods.

\section{INTRODUCTION}

The most recent US national data indicate that in 2014 there were 273500 fires in one-family and two-family homes, leading to 2745 fatal injuries and 8025 non-fatal injuries. ${ }^{1}$ A functioning smoke alarm reduces the risk of fire injuries by more than half; ${ }^{3}$ however, just over half of the houses experiencing fires reported to US fire departments from 2009 to 2013 had a functional smoke alarm that sounded at the time of the fire. ${ }^{2}$

Community smoke alarm distribution programmes in high-fire-risk areas (hereafter, high-risk areas $^{4}$ ) have demonstrated effectiveness to reduce house fire injuries. ${ }^{3}{ }^{5-10}$ Such programmes require significant resources, including supplies and personnel costs. One previous economic evaluation of a distribution programme by fire professionals and volunteers going door-to-door in high-risk areas of Oklahoma City (distribution in 1990 of 10100 alarms to 9291 homes, injury outcomes observed over subsequent five years) reported favourable cost-effectiveness results. ${ }^{9}$ Two studies modelled distribution programmes in hypothetical high-risk communities and reported favourable costeffectiveness results for both giveaway and installation programmes over 10-year and 20-year modelled periods, respectively. ${ }^{10} 11$ A UK study (distribution in 1997-1998 of 20050 alarms to 19950 homes, injury outcomes observed over subsequent two years) of a primarily giveaway-only programme implemented mainly through existing home service workers (eg, nurse visitation staff) reported less desirable health and economic results. ${ }^{12}{ }^{13}$ Authors of the UK study suggested the programme's giveaway approach had not resulted in a sufficient number of alarms installed and maintained. Notably, the UK study randomised households to receive alarms, while the Oklahoma City and modelled studies did not.

Operation Installation (OI) - a long-running and ongoing community-based smoke alarm installation programme in high-risk census tracts in Dallas, Texas-was patterned after the Oklahoma City programme approach; the main differences being that in OI all alarms are installed by OI personnel and the programme uses only lithium-powered ionisationtype smoke alarms. ${ }^{3}$ The aim of this study was to conduct a retrospective cost-benefit analysis of OI during the period the programme was evaluated for effectiveness, comparing the programme's cost to its effectiveness in preventing house fire injuries.

\section{METHODS}

Study information is reported according to Consolidated Health Economic Evaluation Reporting Standards. ${ }^{14}$ This study was a costbenefit analysis that assessed the monetary value of programme benefits compared with programme expenditures; we did not evaluate non-monetary benefits. The choice of analytic model was guided by the assumption that a cost-benefit model would be most relevant to decision makers in other US municipalities considering programmes similar to OI. The main outcome measures were the cost per smoke alarm installed, the net programme cost (or programme cost minus programme benefit), the incremental cost per fire injury averted (or net cost 
divided by net benefit) and the return on programme investment (or the value of benefits divided by programme cost, also interpreted as the return achieved for each dollar invested in the programme). The primary cost perspective for this study was societal, meaning measurable costs to all payers. We also report a combined payers' perspective, which includes only direct programme and medical costs. The time horizon for programme costs can be best interpreted as the average follow-up period of a previously published OI effectiveness study, or 5.2 years, although we included estimated lifetime costs of medical care and lost productivity due to fire injuries. ${ }^{3}$ The choice of health outcome measure-fire injuries averted-was determined by the previous OI effectiveness study. ${ }^{3}$ Estimated long-term medical and lost productivity unit costs were discounted in the reference source by $3 \%{ }^{15}$ All costs are presented as 2013, programme costs recorded annually over a number of years were inflated using the US Consumer Price Index. ${ }^{16}$ This study did not include human subjects.

\section{Programme description}

OI is a collaboration between the Injury Prevention Center of Greater Dallas, the Dallas Fire Rescue Department and the Dallas chapter of the American Red Cross. OI targets houses in high-risk census tracts-defined by high rates of house fire injuries and the bottom quartile of median household income-for smoke alarm installation by fire professionals and accompanying volunteers, along with education for residents. ${ }^{4} 7$ Programme details have been previously reported. ${ }^{3}$

\section{Programme effectiveness}

An observational study of Ol's effectiveness (2001-2011) using an average of 5.2 years of follow-up per household among residents $(n=28570)$ in houses $(n=8134)$ that received OI smoke alarm installation (hereafter, programme houses) observed $68 \%$ (3.1 vs 9.6 per 100000 person-years) fewer fatal and non-fatal fire injuries compared with residents in houses that did not receive alarms (hereafter, non-programme houses). ${ }^{3}$ Regressionadjusted comparison of fire injury rates that controlled for resident and household characteristics were not substantially different from crude observed rates. ${ }^{3}$ Houses in OI were not randomised to control or treatment; non-programme houses were those in the same census tracts that did not receive an installation, whether by virtue of non-response when OI staff visited the house or refusal of installation. OI did not systematically document the presence or functionality of pre-existing smoke alarms in programme and non-programme houses. Evidence from the effectiveness study suggested that significant differences in fire injury incidence occurred during the first five years after smoke alarm installation, followed by a levelling of observed injury rates. A separate follow-up study of OI programme houses $(n=800)$ reported $92 \%$ of houses still had at least one functioning OI smoke alarm at 2 years post installation, but by 10 years post installation that had dropped to $20 \% \cdot{ }^{17}$ Unpublished data from the OI effectiveness study were used to identify medical treatment by type among those residents that sustained fire injuries-for example, the number of residents with non-fatal injuries treated and released from a hospital emergency department (ED) or admitted to hospital, and the number of residents with fatal injuries resulting in death at the fire scene, treated initially in an $\mathrm{ED}$, or admitted to hospital followed by death.

\section{Medical and productivity costs}

National lifetime medical and work loss cost estimates for people with fatal and non-fatal fire injuries by initial treatment location (ie, ED or inpatient) were obtained from the Web-Based Injury Statistics Query and Reporting System, an online cost tool from the CDC. ${ }^{15}$ Monetised quality of life decrements associated with non-fatal injuries were not included. The medical cost estimates represent the average lifetime cost of medical treatment for fire injuries, including initial hospital treatment, follow-up ED visits and hospitalisations, ambulance transportation, ambulatory care, prescription drugs, home healthcare, vision aids, dental visits and medical devices, as well as nursing home and insurance claims administration costs and coroner costs for fatalities. ${ }^{18}$ Lost productivity was valued conservatively using the human capital approach, including lost expected employment compensation and value of household work. This analysis employed national, rather than Texas-specific, cost data due to data availability. Also owing to available data, this study focused on long-term OI effectiveness to reduce fire-related injuries, not residential fires; therefore, the incidence and cost of fire-related property damage were not included in this analysis.

\section{Programme costs}

Detailed cost data associated with OI implementation were obtained from administrative records on programme expenditures from October 2006 through September 2012, which included some years during which the OI effectiveness study was conducted (April 2001-April 2011), as well as more than a year (May 2011-September 2012) that was not included in the effectiveness analysis. Programme expenditures included personnel compensation, an estimated monetary value of volunteer time, ${ }^{19}$ transportation (ie, fire trucks and other vehicles) for fire professionals and volunteers during smoke alarm distribution activities, educational materials for residents, smoke alarms and installation supplies, programme advertisement, administrative supplies and travel for programme staff. Further details on programme costs by category are reported in the online supplementary appendix. Programme expenditures as annually recorded were inflated to 2013 US\$ and not discounted. We summed expenditures over the cost period and divided that total by the total number of alarms installed during the period to estimate the programme's cost per smoke alarm installed.

\section{Analysis}

The total cost of OI was calculated as the estimated cost per smoke alarm installed multiplied by the number of alarms installed during the OI effectiveness study. Rates of injury from the OI study were applied to standardised programme and nonprogramme populations. To calculate the cost of fire injuries, we multiplied unit medical and lost productivity costs by the expected number of injuries by treatment location with and without the programme. Payer perspective total costs included programme costs and the lifetime medical cost of fire injuries. Societal perspective costs included programme costs, the lifetime medical cost and lost productivity cost of fire injuries. The incremental cost per fire injury averted and benefit-cost ratio were calculated from both payer and societal perspectives.

Sensitivity of results to different programme costs and effectiveness was tested in two ways. First, a series of one-way sensitivity analyses and a combined 'worst-case' scenario explored the impact of substantially lesser or greater programme effectiveness, programme costs, medical costs and productivity costs. Second, a threshold analysis explored the values at which programme costs and programme effectiveness would reverse the findings of the base case analysis. 


\section{RESULTS}

The total cost of OI over the cost observation period October 2006-September 2011 was \$1 483618 (table 1). During that time, 25068 smoke alarms were installed at an average cost of $\$ 59.18$ per alarm installed.

Among the population of 28570 residents of 8134 households that received at least one alarm during the OI effectiveness study, an estimated 8.3 fire injuries (2.5 non-fatal and 5.8 fatal) injuries were averted-based on a standardised comparison in terms of 100000 person-years observed among residents of programme versus non-programme houses-at an estimated cost savings of $\$ 116119$ in discounted lifetime total medical care and \$4.9 million in discounted lifetime lost productive value (table 2). The incremental cost per fire injury (fatal and nonfatal) averted through the smoke alarm installation programme from a payer's perspective was an estimated \$128 800 . Including lost productive value in an analysis from the societal perspective resulted in a negative incremental cost per fire injury averted, meaning the programme was cost saving. From a societal perspective, OI is estimated to have saved $\$ 3.8$ million; every $\$ 1$ spent on OI yielded $\$ 3.21$ in averted lifetime costs.

A sensitivity analysis demonstrated that OI would have been cost saving-or a positive return on investment-from a societal perspective whether, in isolation, programme effectiveness, programme costs, medical costs and productivity costs were half to twice as much as assumed (table 3). In a 'worst-case' scenario (in which combined programme effectiveness was half that actually observed, programme costs were twice that actually observed, and medical and productivity costs were half that assumed), the societal cost of the programme was still a modest $\$ 135305$ per fire injury averted (table 3 ).
In a threshold analysis, from a societal cost perspective programme costs could have been over four times higher (or nearly $\$ 250$ per smoke alarm installed) than actually observed or programme effectiveness could have been reduced by $>75 \%$ (or 1.6 fire injuries averted compared with 6.5 fire injuries averted), and the programme still would have been cost saving (results not shown in a table). In combination, programme costs could have been up to twice as high (or \$118.37) and reductions in the fire injury rate among residents of programme households could have been as low as half of that actually observed and the programme still would have been cost saving from a societal perspective (results not shown in a table).

\section{DISCUSSION}

Based on directly observed programme expenditures and smoke alarm installations over several years, as well as observed injury outcomes over an average of $>5$ years post-installation per household, this study suggests OI constituted good value from a payer perspective and provided a substantial return on investment from a societal perspective.

This study benefited from actual expenditures data and longterm comparative data on fire injuries among residents in households that received installed alarms compared with households that did not receive alarms. The programme's estimated cost per alarm installed (\$59.18) is comparable to previous peerreviewed estimates (table 4). Compared with the highest previously estimated cost per alarm installed-which was based on just 1 year of observed costs and installations in one community among 12 communities observed for the study ${ }^{20}$-OI had higher annual costs, a greater number of houses that received installation, a similar average number of alarms installed per

Table 1 Estimated Operation Installation programme cost per smoke alarm installed

\begin{tabular}{|c|c|c|c|c|c|c|c|}
\hline \multirow[b]{2}{*}{ Cost type } & \multicolumn{6}{|c|}{ Programme cost year } & \multirow[b]{2}{*}{ Total } \\
\hline & 2007 & 2008 & 2009 & 2010 & 2011 & 2012 & \\
\hline \multicolumn{8}{|l|}{ Personnel } \\
\hline Firefighters & $\$ 12095$ & $\$ 15538$ & $\$ 22470$ & $\$ 15296$ & $\$ 14493$ & $\$ 11797$ & $\$ 91689$ \\
\hline Fire prevention officers & $\$ 55392$ & $\$ 73093$ & $\$ 53524$ & $\$ 59307$ & $\$ 42378$ & $\$ 18413$ & $\$ 302107$ \\
\hline Education programmes & $\$ 1879$ & $\$ 6073$ & $\$ 23363$ & $\$ 32727$ & $\$ 24869$ & $\$ 0$ & $\$ 88910$ \\
\hline Administrative & $\$ 13708$ & $\$ 37633$ & $\$ 34753$ & $\$ 33805$ & $\$ 25959$ & $\$ 13648$ & $\$ 159505$ \\
\hline Volunteers* & $\$ 1894$ & $\$ 18311$ & $\$ 19754$ & $\$ 19122$ & $\$ 16281$ & $\$ 5863$ & $\$ 81225$ \\
\hline Category total & $\$ 84968$ & $\$ 150647$ & $\$ 153863$ & $\$ 160257$ & $\$ 123980$ & $\$ 49720$ & $\$ 723436$ \\
\hline \multicolumn{8}{|l|}{ Supplies } \\
\hline Installationt & $\$ 133095$ & $\$ 80844$ & $\$ 77237$ & $\$ 98475$ & $\$ 71320$ & $\$ 15735$ & $\$ 476706$ \\
\hline Administrative & $\$ 48617$ & $\$ 7562$ & $\$ 2529$ & $\$ 5145$ & $\$ 647$ & $\$ 0$ & $\$ 64500$ \\
\hline Category total & $\$ 165184$ & $\$ 78366$ & $\$ 70175$ & $\$ 91391$ & $\$ 63110$ & $\$ 13781$ & $\$ 482007$ \\
\hline \multicolumn{8}{|l|}{ Materials } \\
\hline Education & $\$ 9549$ & $\$ 22814$ & $\$ 36212$ & $\$ 20938$ & $\$ 24926$ & $\$ 0$ & $\$ 114439$ \\
\hline Advertisement & $\$ 8758$ & $\$ 37427$ & $\$ 18766$ & $\$ 8136$ & $\$ 1541$ & $\$ 0$ & $\$ 74629$ \\
\hline Category total & $\$ 18307$ & $\$ 60241$ & $\$ 54979$ & $\$ 29074$ & $\$ 26467$ & $\$ 0$ & $\$ 189068$ \\
\hline \multicolumn{8}{|l|}{ Transportation } \\
\hline Transportation & $\$ 2060$ & $\$ 2500$ & $\$ 3214$ & $\$ 3247$ & $\$ 2626$ & $\$ 1188$ & $\$ 14834$ \\
\hline Travel & $\$ 0$ & $\$ 3182$ & $\$ 4334$ & $\$ 6419$ & $\$ 1140$ & $\$ 0$ & $\$ 15074$ \\
\hline Category total & $\$ 2060$ & $\$ 5681$ & $\$ 7547$ & $\$ 9665$ & $\$ 3766$ & $\$ 1188$ & $\$ 29908$ \\
\hline Total & $\$ 287048$ & $\$ 304975$ & $\$ 296156$ & $\$ 302616$ & $\$ 226180$ & $\$ 66643$ & $\$ 1483618$ \\
\hline Alarms installed (n) & & & & & & & 25068 \\
\hline Cost per alarm & & & & & & & $\$ 59.18$ \\
\hline
\end{tabular}


Table 2 Economic evaluation of Operation Installation and supporting data

\begin{tabular}{|c|c|c|c|c|c|c|}
\hline \multirow[b]{2}{*}{ Parameter } & \multirow[b]{2}{*}{ Unit cost } & \multirow[b]{2}{*}{ With programme } & \multirow[b]{2}{*}{ Without programme } & \multicolumn{2}{|c|}{$\begin{array}{l}\text { Difference: with vs } \\
\text { without programme }\end{array}$} & \multirow[b]{2}{*}{ Source } \\
\hline & & & & $\mathbf{n}$ & $\%$ & \\
\hline \multicolumn{7}{|l|}{ Study details (n) } \\
\hline Residents & & 28570 & 28570 & & & Istre (2014) \\
\hline Houses & & 8134 & 8134 & & & Istre (2014) \\
\hline Person-years of follow-up & & 128333 & 128333 & & & Istre (2014) \\
\hline Smoke alarms installed & & 20127 & 0 & & & Istre (2014) \\
\hline Alarms per house, mean (n) & & 2.47 & 0 & & & Calculated \\
\hline \multicolumn{7}{|l|}{ Injury outcomes (per 100000 person-years) } \\
\hline \multicolumn{7}{|l|}{ Non-fatal } \\
\hline Treated in emergency department & & 0.8 & 1.8 & -1.0 & -56 & Unpublished data \\
\hline Admitted to hospital & & 0.8 & 1.8 & -1.0 & -56 & Unpublished data \\
\hline Total (non-fatal) & & 1.6 & 3.5 & -2.0 & -56 & Istre (2014) \\
\hline \multicolumn{7}{|l|}{ Fatal } \\
\hline Died at scene & & 1.6 & 3.5 & -2.0 & -56 & Unpublished data \\
\hline Treated in emergency department & & 0.0 & 1.5 & -1.5 & -100 & Unpublished data \\
\hline Admitted to hospital & & 0.0 & 1.0 & -1.0 & -100 & Unpublished data \\
\hline Total (fatal) & & 1.6 & 6.1 & -4.5 & -74 & Istre (2014) \\
\hline Total & & 3.1 & 9.6 & -6.5 & -68 & Istre (2014) \\
\hline \multicolumn{7}{|l|}{ Injury outcomes (n residents) } \\
\hline \multicolumn{7}{|l|}{ Non-fatal } \\
\hline Treated in emergency department & & 1.0 & 2.3 & -1.3 & -56 & Calculated \\
\hline Admitted to hospital & & 1.0 & 2.3 & -1.3 & -56 & Calculated \\
\hline Total (non-fatal) & & 2.0 & 4.5 & -2.5 & -56 & Istre (2014) \\
\hline \multicolumn{7}{|l|}{ Fatal } \\
\hline Died at scene & & 2.0 & 4.5 & -2.5 & -56 & Calculated \\
\hline Treated in emergency department & & 0.0 & 1.9 & -1.9 & -100 & Calculated \\
\hline Admitted to hospital & & 0.0 & 1.3 & -1.3 & -100 & Calculated \\
\hline Total (fatal) & & 2.0 & 7.8 & -5.8 & -74 & Istre (2014) \\
\hline Total & & 4.0 & 12.3 & -8.3 & -68 & Istre (2014) \\
\hline \multicolumn{7}{|l|}{ Programme and injury costs } \\
\hline \multicolumn{7}{|l|}{ Installation programme } \\
\hline Per alarm & $\$ 59.18$ & $\$ 1191192$ & $\$ 0$ & $\$ 1191192$ & 100 & Table 1 \\
\hline \multicolumn{7}{|l|}{ Injuries: medical care } \\
\hline \multicolumn{7}{|l|}{ Non-fatal } \\
\hline Treated in emergency department & $\$ 1846$ & $\$ 1846$ & $\$ 4199$ & $-\$ 2353$ & -56 & CDC (2010) \\
\hline Admitted to hospital & $\$ 31076$ & $\$ 31076$ & $\$ 70680$ & $-\$ 39604$ & -56 & CDC (2010) \\
\hline Total (non-fatal) & & $\$ 32922$ & $\$ 74878$ & $-\$ 41956$ & -56 & Calculated \\
\hline Fatal (a) & $\$ 12791$ & $\$ 25582$ & $\$ 99744$ & $-\$ 74162$ & -74 & CDC (2010) \\
\hline Total medical care & & $\$ 58504$ & $\$ 174623$ & $-\$ 116119$ & -66 & Calculated \\
\hline Injuries: lost productivity & & & & & & \\
\hline Non-fatal & & & & & & \\
\hline Treated in emergency department & $\$ 3863$ & $\$ 3863$ & $\$ 8786$ & $-\$ 4923$ & -56 & CDC (2010) \\
\hline Admitted to hospital & $\$ 37684$ & $\$ 37684$ & $\$ 85709$ & $-\$ 48025$ & -56 & CDC (2010) \\
\hline Total (non-fatal) & NA & $\$ 41547$ & $\$ 94495$ & $-\$ 52948$ & -56 & Calculated \\
\hline Fatal & $\$ 835288 \dagger$ & $\$ 1670576$ & $\$ 6513577$ & $-\$ 4843001$ & -74 & CDC (2010) \\
\hline Total lost productivity & & $\$ 1712123$ & $\$ 6608072$ & $-\$ 4895949$ & -74 & Calculated \\
\hline Total injury cost & & $\$ 1770627$ & $\$ 6782694$ & $-\$ 5012067$ & -74 & Calculated \\
\hline Total cost & & & & & & \\
\hline Payer perspectiveł & & $\$ 1249696$ & $\$ 174623$ & $\$ 1075073$ & 616 & Calculated \\
\hline Societal perspective§ & & $\$ 2961819$ & $\$ 6782694$ & $-\$ 3820876$ & -56 & Calculated \\
\hline Economic evaluation & & & & & & \\
\hline Incremental cost per fire injury averte & & & & & & \\
\hline Payer perspective & & $\$ 128800$ & & & & Calculated \\
\hline Societal perspective & & $-\$ 457763$ & & & & Calculated \\
\hline Return on investment (or benefit-cos & & & & & & \\
\hline Payer perspective & & $-\$ 0.90$ & & & & Calculated \\
\hline Societal perspective & & $\$ 3.21$ & & & & Calculated \\
\hline
\end{tabular}

Costs presented as 2013 US\$.

tReference source for the cost of medical care for fatal fire injuries does not distinguish between treatment locations.

₹Calculated as programme cost+medical costs.

$\S$ Calculated as programme cost+medical costs+lost productivity.

ๆCalculated as (cost with programme - cost without programme)/(fire injuries with programme - fire injuries without programme).

** Calculated as (programme benefit/programme cost), can be interpreted as the return per $\$ 1$ invested in the programme. 
Table 3 Sensitivity analysis

\begin{tabular}{|c|c|c|c|c|}
\hline \multirow[b]{2}{*}{ Input } & \multicolumn{2}{|c|}{ Net programme cost by cost perspective } & \multicolumn{2}{|c|}{$\begin{array}{l}\text { Incremental cost per injury averted by } \\
\text { cost perspective }\end{array}$} \\
\hline & Payer & Societal & Payer & Societal \\
\hline Base case & $\$ 1075073$ & (\$3820 876) & $\$ 128800$ & $(\$ 457763)$ \\
\hline \multicolumn{5}{|l|}{ Programme effectiveness } \\
\hline $50 \%$ of base case & $\$ 1133132$ & (\$1 314842$)$ & $\$ 135756$ & $(\$ 157526)$ \\
\hline $200 \%$ of base case & $\$ 958954$ & (\$8 832 943) & $\$ 114888$ & (\$1 058 239) \\
\hline \multicolumn{5}{|l|}{ Programme cost } \\
\hline $50 \%$ of base case & $\$ 479477$ & (\$4 416472$)$ & $\$ 57444$ & (\$529 119) \\
\hline $200 \%$ of base case & $\$ 2266264$ & (\$2 629684$)$ & $\$ 271512$ & $(\$ 315052)$ \\
\hline \multicolumn{5}{|l|}{ Medical costs } \\
\hline $50 \%$ of base case & $\$ 1133132$ & $(\$ 3762817)$ & $\$ 135756$ & (\$450 808) \\
\hline $200 \%$ of base case & $\$ 958954$ & (\$3936 994) & $\$ 114888$ & $(\$ 471675)$ \\
\hline \multicolumn{5}{|l|}{ Productivity costs } \\
\hline $50 \%$ of base case & $\$ 1075073$ & (\$1 372 901) & $\$ 128800$ & (\$164 482) \\
\hline $200 \%$ of base case & $\$ 1075073$ & (\$8 716 825) & $\$ 128800$ & 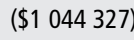 \\
\hline $\begin{array}{l}\text { 'Worst-case' scenario, combining: } \\
\text { effectiveness } 50 \% \text { of base case } \\
\text { programme cost } 200 \% \text { of base case } \\
\text { Medical costs } 50 \% \text { of base case } \\
\text { Productivity costs } 50 \% \text { of base case }\end{array}$ & $\$ 2353353$ & $\$ 1129366$ & $\$ 281946$ & $\$ 135305$ \\
\hline
\end{tabular}

Table 4 Comparison of results from selected previous studies

\begin{tabular}{|c|c|c|c|c|c|c|}
\hline Study & Haddix (2001) & Ginnely (2005) & Parmer (2006) & Liu (2012) & Diamond-Smith (2014) & Present study \\
\hline Distribution year & 1990 & 1997-1998 & 2002-2003 & NR & NR & 2006-2011 \\
\hline Cost year & 1990 & 1999 & 2002 & 2011 & NR & 2013 \\
\hline Location & Oklahoma City, USA & London, UK & 12 communities, USA & Model & Model $^{*}$ & Dallas, USA \\
\hline Distribution type & Giveaway & Giveaway & Installation & Both & Installation & Installation \\
\hline Alarms (n) & 10100 & 20050 & $95-1260$ & NR & 260 & 24127 \\
\hline Houses (n) & 9291 & 19950 & $56-604$ & 706 & 10000 & 8134 \\
\hline Alarms per house $(n) \dagger$ & 1.1 & 1.0 & $1.7-2.1$ & NR‡ & $<0.1$ & 2.5 \\
\hline Total programme cost & $\$ 530611$ & f157 823 & $\$ 199618-255425$ & $\$ 41987(\mathrm{~g})$ to $\$ 105053(\mathrm{i})$ & $\$ 6845$ & $\$ 1419502$ \\
\hline \multicolumn{7}{|l|}{ Average cost per alarm } \\
\hline As originally reported & $\$ 52.54$ & $£ 7.87$ & $\$ 60.44-218.92$ & $\$ 50(\mathrm{~g})$ to $\$ 240(\mathrm{i}) \S$ & $\$ 26.339$ & $\$ 57.37$ \\
\hline As 2013 US\$ & $\$ 84.05$ & $\$ 16.85$ & $\$ 76.00-275.28$ & $\$ 51.75(\mathrm{~g})$ to $\$ 248.41(\mathrm{i})$ & $\$ 26.33$ & $\$ 59.18$ \\
\hline Injury observation period & 5 years & 23.9 months & NA & 20 years & 10 years & 5.2 years \\
\hline \multicolumn{7}{|c|}{$\begin{array}{l}\text { Inflated using price indices for US Gross Domestic Product }{ }^{25} \text { and converted from foreign currency to US\$ using http://www.xe.com (f1=\$1.58 on } 1 \text { July } 1999 \text { ). } \\
\text { *Based in part on data ('standard programme' scenario data depicted in this table) from a programme in Baltimore, USA. } \\
\text { †Calculated. } \\
\text { ¥Model assumed giveaway and installation programmes would reduce the number of houses without a functional smoke alarm by } 30 \% \text { and } 80 \% \text {, respectively. } \\
\text { §Cost year not reported in reference study, assumed approximately } 2011 \text { given the study's publication date. } \\
\text { ICost year not reported in reference study, assumed approximately } 2013 \text { given the study's publication date. } \\
\text { (g), giveaway; (i), installation; NA, not applicable; NR, not reported. }\end{array}$} \\
\hline
\end{tabular}

house and a far lower average cost per alarm installed. The OI estimated cost per alarm in the present study was also based on a far greater number of data years. OI may have benefited from programme experience and economies of scale that brought down the programme's overall cost per alarm installed; economies of scale in a smoke alarm distribution programme has been documented empirically in a previous study. ${ }^{20}$ Cost per smoke alarm was the most meaningful comparable measure among previous peer-reviewed studies of actual or modelled community smoke alarm installation programmes. Owing to different injury observation periods, medical and lost productivity cost valuation, and reporting of economic evaluation measures (eg, incremental cost-effectiveness ratios vs willingness-to-pay thresholds) in previous studies, we have not attempted to compare the incremental cost-effectiveness ratios reported in this study to previous studies.
The difference between this study's estimated $\$ 59.18$ per smoke alarm cost and a briefly mentioned cost of $\$ 56.71$ per smoke alarm in a previous OI paper ${ }^{21}$ is due to this study's application of the actual-rather than inflation-adjusted-estimated 2013 annual value of volunteer time over the entire cost observation period, as well as this study's application of the national, rather than Texas, estimated volunteer wage rate.

This study had a number of limitations. Based on available data, we were not able to include all conceivable costs of fire injuries. For example, costs to injury victims' families were not included; including these costs would have made the programme more cost-beneficial. Available programme cost data covered only some of the years of the effectiveness study to which we applied the cost data; however, it did represent a majority of the years that were covered in the previously published effectiveness study. We included direct expenditures of OI 
during a mature operational phase of the programme, which may not be generalisable to costs in the initial phase of such a programme. It is possible, and even likely, that the initial cost of a similar programme in an area without similar expertise and infrastructure would be higher than we have estimated here. However, sensitivity analysis reported cost savings from the OI programme would have occurred even if programme costs had been instead $\$ 250$ per alarm installed, rather than the observed (\$59.18); or nearly the highest cost per alarm reported among previous studies (table 4).

We used observed injury incidence data from an observational study of OI programme versus non-programme houses, although a major limitation of the effectiveness study data is that houses were not randomised to receive smoke alarms in that study. It is possible that the same factors that influenced households' availability and willingness to have alarms installed by OI professionals could be linked to the lower observed fire injury rates among those households; in other words, without a randomised trial there is a risk that the lower observed injury rate among residents in programme houses was misattributed to OI alarm installation in the effectiveness study.

We used unit costs for medical care and lost productivity due to fire injuries calculated at the national level. Unpublished data from 2010-2015 obtained from a local medical facility in Dallas, Texas, suggested higher local average costs per ED-treated and admitted patients than the national unit costs we used (unpublished data obtained from Parkland Hospital, Dallas, Texas), Because more fire injuries occurred among residents of non-programme houses, if medical costs were higher than we have assumed here the cost savings associated with OI would have been greater (table 3). But even if medical costs were instead just $50 \%$ of what we assumed here, the OI programme still would have demonstrated cost savings (table 3).

This study's estimated programme costs were specific to Dallas, Texas, which may limit the generalisability of the estimates. Labour or personnel costs constituted the largest cost category in our estimated cost per smoke alarm. The most recent available data from the National Compensation Survey indicate that average hourly wages for all workers in Dallas, Texas, are $1 \%$ below the national average, and wages for firefighters are $4 \%$ below the national average. ${ }^{22}$

Despite study limitations, a community smoke alarm installation programme in Dallas, Texas, appears to have been highly cost-beneficial. This study was based on what appears to be the longest directly observed injury outcomes and costs associated with a smoke alarm installation programme documented in the literature. This study's results support previous studies that have indicated the value of smoke alarm installation programmes in communities at particular risk for residential fires, which primarily includes households with various socioeconomic disadvantages. ${ }^{23} 24$ Recommended for future study are the effectiveness and cost of follow-up activities to maintain the now relatively well-established cost-benefit of smoke alarm

What is already known on the subject?

- Thousands of people die or sustain serious injuries from house fires every year in the USA.

- Community smoke alarm installation programmes have demonstrated effectiveness to reduce fire deaths and injuries.

\section{What this study adds?}

Based on actual programme costs and observed reductions in fire deaths and injuries from a long-term observational follow-up study of a community smoke alarm installation programme-Operation Installation in Dallas, Texas-this study supports previous studies in estimating that such programmes can be cost saving; or a positive long-term return on investment.

installation programmes, such as smoke alarm maintenance and replacement, and fire safety education among new neighbourhood cohorts.

Acknowledgements The authors thank Robyn Manning of the Decision Support Department, Parkland Hospital, for providing average local cost data for fire-related injuries for comparison to the national cost data.

Contributors MAY led the study design and interpretation of results, conducted data analysis, drafted and edited the manuscript, and approved the final manuscript as submitted. CP led the study design and interpretation of results, conducted data analysis, drafted and edited the manuscript, and approved the final manuscript as submitted. MAMC, EC, JJB and TOP Jr assisted with data collection, edited the manuscript and approved the final manuscript as submitted. SS-S assisted with the study design, edited the manuscript and approved the final manuscript as submitted. CF and GRI assisted with the study design and interpretation of results, edited the manuscript and approved the final manuscript as submitted.

Funding Funded in part from Grant 1 H28 CE000840-01, National Center for Injury Prevention and Control, Centers for Disease Control, US Department of Health and Human Services and Subcontract \#727922 from the University of Washington, Seattle, Washington.

Disclaimer The findings and conclusions in this report are those of the authors and do not necessarily represent the official position of the Centres for Disease Control and Prevention.

Competing interests None declared.

Provenance and peer review Not commissioned; externally peer reviewed.

Data sharing statement Final results are calculable from data presented in the tables. Unit inputs (ie, costs and effectiveness) are primarily derived from published sources as cited. Data and calculations that were used to estimate programme costs by category and year are available from authors upon request.

\section{REFERENCES}

1 Haynes H. Fire loss in the United States during 2014. Quincy, Massachusetts: National Fire Protection Association, 2015

2 Ahearns M. Smoke alarms in U.S. home fires. Quincy, Massachusetts: National Fire Protection Association, 2015

3 Istre GR, McCoy MA, Moore BJ, et al. Preventing deaths and injuries from house fires: an outcome evaluation of a community-based smoke alarm installation programme. Inj Prev 2014;20:97-102.

4 Istre GR, McCoy MA, Osborn L, et al. Deaths and injuries from house fires. N Engl J Med 2001;344:1911-16.

5 Ballesteros MF, Jackson ML, Martin MW. Working toward the elimination of residential fire deaths: the Centers for Disease Control and Prevention's Smoke Alarm Installation and Fire Safety Education (SAIFE) program. J Burn Care Rehabil 2005;26:434-9.

6 Harvey PA, Aitken M, Ryan GW, et al. Strategies to increase smoke alarm use in high-risk households. J Community Health 2004;29:375-85.

7 Mallonee $S$, Istre GR, Rosenberg $M$, et al. Surveillance and prevention of residential-fire injuries. N Engl J Med 1996;335:27-31.

8 Ta VM, Frattaroli S, Bergen G, et al. Evaluated community fire safety interventions in the United States: a review of current literature. J Community Health 2006:31:176-97.

9 Haddix AC, Mallonee $S$, Waxweiler $R$, et al. Cost effectiveness analysis of a smoke alarm giveaway program in Oklahoma City, Oklahoma. Inj Prev 2001;7:276-81.

10 Diamond-Smith N, Bishai D, Perry E, et al. Economic evaluation of smoke alarm distribution methods in Baltimore, Maryland. Inj Prev 2014;20:251-7.

11 Liu Y, Mack KA, Diekman ST. Smoke alarm giveaway and installation programs: an economic evaluation. Am J Prev Med 2012;43:385-91. 


\section{Original article}

12 Ginnelly L, Sculpher M, Bojke C, et al. Determining the cost effectiveness of a smoke alarm give-away program using data from a randomized controlled trial. Eur J Public Health 2005; 15:448-53.

13 DiGuiseppi C, Roberts I, Wade A, et al. Incidence of fires and related injuries after giving out free smoke alarms: cluster randomised controlled trial. BMJ 2002;325:995.

14 Husereau D, Drummond M, Petrou S, et al. Consolidated Health Economic Evaluation Reporting Standards (CHEERS)--explanation and elaboration: a report of the ISPOR Health Economic Evaluation Publication Guidelines Good Reporting Practices Task Force. Value Health 2013;16:231-50.

15 US Centers for Disease Control and Prevention. Web-based Injury Statistics Query and Reporting System (WISQARS), Cost of Injury Reports 2010, Nonfatal Hospitalized Injuries, Both Sexes, All Ages, United States, Intent: Sexual Assault 2010 [cited 2015 December 11]. http://www.cdc.gov/injury/wisqars/index.html

16 US Bureau of Labor Statistics. Consumer Price Index-All Urban Consumers, U.S. city average (Series ID: CUUR0000SA0,CUUS0000SA0) 2016. http://www.bls. gov/cpi/data.htm

17 McCoy MA, Roper C, Campa E, et al. How long do smoke alarms function? A cross-sectional follow-up survey of a smoke alarm installation programme. Inj Prev 2014;20:103-7.
18 Lawrence B, Miller T. Medical and work loss cost estimation methods for the WISQARS cost of injury module. Calverton, Maryland: Pacific Institute for Research and Evaluation, 2014. http://www.cdc.gov/injury/wisqars/pdf/wisqars_cost_ methods-a.pdf

19 Independent Sector. The value of volunteer time: US total 2013 2016. https://www. independentsector.org/volunteer_time

20 Parmer JE, Corso PS, Ballesteros MF. A cost analysis of a smoke alarm installation and fire safety education program. J Safety Res 2006;37:367-73.

21 Stephens-Stidham S, McCoy M, Roper C, et al. Using the RE-AIM framework to evaluate a community-based smoke alarm installation program. J Prev Med Care 2016;1:P.1-7

22 US Bureau of Labor Statistics. National Compensation Survey database data query: Hourly mean earnings for all workers and firefighters in Dallas, TX and United States. 2010. http://www.bls.gov/ncs/ocs/data.htm

23 Shai D. Income, housing, and fire injuries: a census tract analysis. Public Health Rep 2006;121:149-54.

24 Shai D, Lupinacci P. Fire fatalities among children: an analysis across Philadelphia's census tracts. Public Health Rep 2003;118:115-26.

25 US Bureau of Economic Analysis. Table 1.1.4. Price Indexes for Gross Domestic Product 2015 [updated 22 December 2015. http://www.bea.gov/itable/ 